\title{
"The Future can only be Imagined" - Innovation in Farm Tourism from a Phenomenological Perspective
}

\author{
Berit Brandth $^{1}$ and Marit S. Haugen ${ }^{*}, 2$ and Britt Kramvig ${ }^{3}$ \\ ${ }^{I}$ Department of Sociology and Political Science, Norwegian University of Science and Technology and Centre for Rural \\ Research, N-7491, Trondheim, Norway \\ ${ }^{2}$ Centre for Rural Research, N-7491, Trondheim, Norway \\ ${ }^{3}$ Department of Sociology, Political Science and Community Planning, University of Tromsø, N-9293 Tromsø, Norway
}

\begin{abstract}
This article relates to the fast growing research literature on innovation by adopting a phenomenological perspective of change and how change comes about. We visited nineteen farms in Norway in a project on farm-based tourism. Results show highly differentiated products but similar routes in transforming a farm no longer seen as economically viable, into a way of doing life and doing work that brings a complex of considerations together. The concept of imaginative horizons is used and seen as characteristic of the transformative process of turning the farm into a farm based tourist enterprise. The same transformation becomes a way of keeping the relationship and interdependence between the past and the present vivid and meaningful.
\end{abstract}

Keywords: Tourism, innovation, improvisation, farm-tourism, rural tourism, rural development.

\section{INTRODUCTION}

This article focuses on the process of product innovation in small scale rural tourism enterprises. Doing things differently, exploring new avenues, collaborating effectively and taking risks are all important aspects of developing the tourism industry. In face of the extensive character of tourism in the world and the intensification of innovation activities, there has been surprisingly little research combining the two fields [1]. The last decade has, however, seen an emerging literature on tourism innovation where innovation theory has been used to describe activities within tourism. As innovation theory was developed in relation to manufacturing, it has been asked whether the concept of innovation is applicable to the service sector [2]. The main objection has been that service production has an interactive and intangible character and that this influences innovation activities [3]. Hjalager [4] suggests that the concept can be used, but that it needs to be adapted and subdivided in order to be appropriately applied in research on the tourism and leisure sector. Innovation is an elusive term that can take many forms.

Researchers on innovation in tourism have, on the one hand, been optimistic regarding the tourism industry's potential to renew itself and innovate [5]. On the other hand, it has been claimed that the tourism industry's innovative ability is low and that it needs to improve considering the competitiveness of the sector [6]. Many firms within tourism belong to the so-called 'experience economy' [7]. Such enterprises are found to be generally more innovative than other tourist businesses [8]. Studies have further documented that the innovation process in tourism is quite unsystematic and incremental, based on practice rather than on R\&D and

*Address correspondence to this author at the Centre for Rural Research, N7491, Trondheim, Norway; Tel: +4773591734; Fax: +4773591275; E-mail: Marit.Haugen@rural.no technology [cf. 9-12]. Innovations in tourism can be fairly minor and exhibit gradual changes rather than distinct jumps [13].

Little innovation research has focused on small-scale (micro) tourism enterprises in rural areas. In Norway and many other countries as well, there has been increasing demand for diversification of traditional sectors like the primary industries, and encouraging innovation and tourism in these industries is seen as important for maintaining robust populations and economic viability in rural areas.

Rønningen [13] who has done a literature review of research on innovation in rural tourism firms, points out that firm size and lack of knowledge may explain the low innovation capacity in rural tourism. What seems to strengthen innovative ability is cooperation between firms and public grants, he concludes. Some ongoing studies in Norway have been concerned to find out what promotes and hinders innovativeness in rural tourism firms [14]. Contrary to expectations from the literature, a conclusion is that innovation among rural firms is high. Cooperation, market information and actions to increase the firms' competence seem to be particularly important in enhancing innovative capacity [13]. Nybakk and Hansen [15] who have studied innovation in nature-based tourist enterprises, point to the importance of entrepreneurial attitudes and suggests that policies that limit risk can serve to make such enterprises more innovative. In a later article the antecedents of innovations in nature-based tourist enterprises are their concern [16]. Results show that social networking and a learning orientation have a positive impact on innovativeness.

In this paper we focus on a special type of small-scale tourist firms, namely enterprises that are developed from an existing farm - also characterized as 'life-style businesses' [15]. They are further characterized by being based on the 
household. Turning the farm, often owned by the family for generations, into a tourist enterprise is an innovative process brought about by various concerns. Rather than studying this process as a necessary adaptation to shifting economic and political conditions in agriculture, we will in this article put focus on the creativity involved. For this we choose a phenomenological perspective, studying innovation from the actors' point of view. We are interested in what characterizes the innovation process in farm tourism. How and from what are ideas developed? What imaginings, considerations, limits, and vulnerabilities is the process based on?

\section{THEORETICAL FRAMEWORK AND CONCEPTS}

Taking phenomenology as a starting point, in this article innovation will be seen as an embodied and existential change balancing moral and ethical obligations toward the community, family, farm tradition, the surrounding natural environment as well as towards oneself. Innovation is generally connected to that which is "new" and stands out as different in relation to conventions. But according to Ingold and Hallam [17], it is necessary to challenge the polarity between novelty and conventions - between the innovation dynamic of the present and the traditionalism of the past. Innovations, at least as they are articulated by innovation programs, are associated with the creation of a plan that sets an idea in motion.

The classic innovator was viewed as someone with a bright idea. The idea that innovation is individual has been part of western discourse since the eighteen century [18]. The personalization of authorship was intensified in the European Romantic movement, in contrast to the idea of creativity as generated through social relations. Innovation later became reserved for the economic exploitation and profitability of ideas - not the creation of ideas themselves [19]. Much literature on innovation has been strongly connected to science and technology, seeing art and creativity as something different. Not only different; there was a hierarchy that established the relationship between science and technology on the one hand and culture, art, and creativity on the other. But as Meyer [20] argues, we will not understand the innovative processes if we do not challenge the differences that were made and still are being made within the discourse of modernity.

Innovation does not, as some within the "funky business" literature would argue [21], come from the autonomous individual's capacity for creativity. To view innovation as a matter of isolated individual action or entrepreneurship is not sufficient. Innovation as well as creativity are relational activities, they go on along the "way of life" and are entangled and mutually responsive [17 p. 7]. In a phenomenological perspective, innovations are seen as the outcome of relations between people who give each other the trust needed for something not set, something that may be vague, dreamlike, imaginative and beyond the horizon to be articulated.

In this article we want to take inspiration from Ingold and Hallam [17] who see "innovation as an ongoing process where people create themselves and one another, forging their histories and traditions as they go along" (p. 6). The forward movement of keeping life going involves a good measure of creative improvisation, where improvisation could be understood as,

"... adjustments of posture, pace and
bearing by which one's movement is
attuned on the one hand to that of
companions with whom one wishes to keep
abreast or in file, and on the other to
strangers coming from different directions
with whom one does not wish to collide"
$[17$ p.7].

This attunement is not only limited to people as it can also be applied to time and place [22].

Change is what we observe when we look back, and tradition does not need to be a constraining factor to innovation, but can also be an enabling one. As Hastrup [23] argues, this has implications for how to identify agency and its temporality. All actions contribute to the emerging of being where the agent is constantly in a process of reconciliation with the past. "Creative agency brings the unprecedented into effect by way of imaginative power and thus expands the community's awareness of itself. The expansion is possible due to the inherent flexibility of the social" (p. 200). What is new then must also contain a sense of semantic and emotional newness, in which others are prepared to take an interest. And according to Hastrup [23] anticipation and creativity are linked with imagination, and imagination itself plays with time.

There is a critical turn in social science influenced by a focus on mobility [24, 25]. The "new mobilities" paradigm problematizes two sets of existing theory. It undermines a sedentary theory that treats as normal stability, meaning and place, and as abnormal distance, change and placelessness [25 p. 208]. In addition it highlights how social science has failed to consider the overwhelming impact of mobility in the socio-technical systems that organize flow of information, population, risk and disaster, images as well as dreams. The mobility paradigm emphasises that all places are tied into thin networks of connections that stretch beyond each place and mean that nowhere can be an "island". Inspired by Jackson [26] we would frame mobility as "excursions" not only because mobility involves breaking with settled routines and the everyday, but because the image of a journey suggests that thought is always on the way, where views are perpetually tested by encounters with others. Throughout his book, Excursions, Jackson is focusing on the struggles and quandaries of everyday life, investigating gaps such as those between insularity and openness, between the things over which we have some control and the things over which we have none. Humans set out to make excursions -excursions towards an imaginative horizon. We think innovation processes can be read in this vocabulary.

The concept of 'imaginative horizons' was introduced by Crapanzano [27] in order to come to terms with cultural creativity and the process of imagination. This is as Crapanzano formulates it; "a concern with openness and closures, with the ways in which we construct horizons that determine what we experience and how we interpret what we experience" (p. 2). He goes on:

"my point is that when a horizon and
whatever lies beyond it are given an 
articulate form, they freeze our view of the reality that immediately confronts us fatally I'd say, were it not for the fact that once that beyond is articulated, a new horizon emerges and with it a new beyond" (p. 2).

The dialectic between openness and closure is an important dimension of human experience, Crapanzano argues. This relates to the idea of movement. And following the phenomenology framed by Ingold [28] and Jackson [26], movement is seen as connected to embodiment; to desire as well as fear - and with movement also can come a sense of displacement. Displacement relates to a sense of imbalance between the self and the community or the landscape the embodied self dwells in, or feels rejected from.

In this article we will focus on the creative, improvisational aspects of the innovation process. Ingold and Hallam [17] conceptualise creative improvisations as generative in the sense that they give rise to new social and cultural processes; as relational being responsive to the performance of others; and as temporal, embodying a certain duration. Further, they see them as embedded in the way we work, our practice when keeping life going.

Drawing on the theoretical framework above, we are concerned to find out what characterizes the innovative process which turns the farm into a tourist enterprise. In what ways are relations important? What are the relationships between novelty and conventions? What are the horizons and their closures?

\section{MATERIALS AND METHODOLOGY}

This article is part of an empirical study of farms that are engaged in farm tourism. The analysis is based on interviews with farmers and previous farmers involved in tourist hosting in Norway. The interviews were conducted in the period between 2006 and 2008, on the farm premises, most of the time with both husband and wife present, but sometimes with only one of them. The interviews lasted between one and three hours each, and were recorded and later transcribed for analysis. Getting a feel for farm site and the business when visiting for the interview has helped to make the data richer and more open to ethnographic analysis.

The total sample consists of 19 farms from various districts in Norway. Criteria for choosing the cases were that the farmers had personal experience of building up the new enterprise. The majority of farmers in Norway cannot make a living from farm production without having additional income. This has also been the case for our sample, as both women and men have held part-time jobs outside the farm for longer or shorter periods. Ten of the farms combine farming and tourism while the remaining nine have renounced conventional farm production and rely on tourism only.

Some of the farm enterprises are situated in mountainous areas, some in forests and some by the sea - from Sápmi ${ }^{1}$ to

\footnotetext{
${ }^{1}$ Norway is a state established on the territory of two peoples; the Sami and the Norwegian. The Sami name given to the land of the Sami people is
}

the south, inland as well as coastal. Some have been in the tourist business for less than five years, others for more than twenty. The farms offer diversified products, adapted to various groups of customers. Accommodation and food are offered by nearly all, in addition to activities such as fishing, hunting, mountain hiking, guided tours, canoeing, courses, cultural activities, horseback riding, and many more.

The farms are family based, in some cases with two and three generations working together. Many of the farms have been in the same family for generations. Ages of the farm couples range from the $20 \mathrm{~s}$ to the $60 \mathrm{~s}$. Their educational level is fairly high. Some of them are in-migrants to the rural community. Others are return migrants who have inherited the farm and want to do something other than conventional farming.

\section{RESULTS}

We start the analysis with a case description of two of the farms.

\section{Seaside Farm}

When you follow the road that many tourist follows, E6 (the European road 6) you end up, as do 200000 other tourists each year, in North Cape. On the cliff named "the top of the world" by the tourist administration, but given the name "Davvi Njarga" ${ }^{2}$ " by the Sami siidas, that are bringing their herds of reindeer to the island for summer pasture, as generations have done before them. But then if you take off to the left, following a small modest sign a few hours before North Cape - you will find a closed down farm with a peaceful view toward the ocean and the glacier on the island on the horizon.

Kari and Henrik are running the tourist enterprise. Some years ago because of a worn down body, the husband decided that the animals had to go and that he and his wife would continue running the farm as a tourism enterprise. At a respectful distance from the farmhouse where they live are ten different cottages, a reception-house, a barn, a roofed fireplace, a boathouse with fishing equipment, a guttingbench and life jackets. On the pier there are rows of boats ready to be taken out in the fjord. All these buildings and investments were done when they had acquired the capital and when they considered themselves to have the experience needed to expand even more. The enterprise was built step by step where they needed to "feel how the summer would run" and how their body reacted in regard to sickness, tiredness and energy levels after the high season. The expansion of the business can be seen as negotiation of relations with others where the space for improvising was the total matrix of relations in which the people as well as ideas are embedded and into which it extends, and whose unfolding is constitutive of the process of social lift [17]. One important 'other' that was part of the consideration, was the social and cultural sustainability of the village and the landscape.

Sápmi; and is a area that crosses the borders between the Nordic countries all the way into the Russian arctic territory.

${ }^{2}$ Davvi Njarga can be translated as the northern half island. 
The couple emphasizes the importance of not setting up a tourist attraction that would be in obvious competition or threat to the local resource management system and hence to the interest of the community they considered themselves a part of. On a practical level that meant that they did not highlight fishing as an activity in order not to create controversy with the local fishermen who had their regular fishing-ground out in the fjord. When guests arrived, they were given an introduction program where they were told how to use the equipment, the boats, the gear and how to treat the catch respectfully, if they got something going out fishing. Visitors were not told about eagles' nests, Sami secret places, or highly valued Cloudberry moors, and by not being revealed they were respected as part of the ground for local, but often informal, nature and resource management systems.

Inventions as well as investments on the farm had been ongoing over a period of twenty years. These small-scale investments and innovative processes also took care of their need "for freedom" - highly valued by both husband and wife - as making investments they could not afford, would give investors considerable decision-making authority in regard to the development of the future of the enterprise. The reason for making them was obvious; "the most important input in setting up a tourist enterprise is the willingness to give something of yourself". Henrik continued:
"You need the willingness and you need to find delight in being with other people. That is the most important qualification. Besides this you need to be willing to learn - both some language and something about service. But still I do think that the most important thing is to try it out and then reflect upon your own reaction - is this something I can do? Am I capable of giving myself to other people? I believe that these are qualities you are born with or not".

A traditional small building no longer in use was their starting point and the opening of horizons. The closure came when new ideas had been considered in regard to the sustainability of the local resources as well as the interest of others in the community. Entering new horizons, they did not have a fixed plan from the beginning; the idea was not even formulated clearly and their capacity to take up new challenges was fragile. Their embodied reactions to what was new, prompted them how to move on. The closure also came from how much of themselves they could invest in relation to their guests. Henrik said:

\footnotetext{
"You get people really close, you know, and have to open yourself up to other people when you are a host in a small-scale enterprise. This is unfamiliar for a person who has been a farmer. That is a fairly lonely job, where each person sits on his own tractor and where we see each other at the dinner-table. So, in the beginning you need to handle yourself with care.....I think the most important challenge is to find a way to be yourself, even in relation to the guests. And not create something artificial. That is very important".
}

After the first period, when people entered their house to make reservation or ask questions, they built a receptionhouse in order to create distance. When the season was over and they had the feeling that "they were happy to have them out of their home" they knew that they had let people in, more than they could handle and that this wore them out. Then they knew that they had not set enough restrictions, and having a building for organizing the relations with the guests became part of the making of distance.

\section{Mountain Farm}

The mountain farm is situated in a remote mountainous area in the south-Sami region of Norway. Tore's childhood dream was to become a Sami. Perhaps as compensation for the impossible dream, he bought a run-down farm and decided to become a farmer. Before that, he took a Master's degree in Biology with a major on arctic reindeer. Having become owner of a ramshackle farm he started fixing the buildings and he went in for goat keeping, as goats can roam around freely and come down to be milked in the evening. He married in the early 1980s. His wife, Inger, who came from the city to work as a teacher in the community, fell in love not only with the farmer, but also with the place that she found "utterly idyllic". After four years three children were born, the fourth child some ten years later. Tore and Inger are a hard-working couple with many dreams and ideas. Commenting on the early days of their partnership, Inger says:
"We saw so many possibilities, and we wanted to make something more out of it (the farm) even if we had 100 goats. (...) This local community is a bit marginal, and we wanted to create more. So, we ended up with a fish farm, a land based fish farm for arctic char. It was a trial and error adventure."

They definitely did not "end up" there. They wanted to process the fish further themselves and concentrated on the production of rakefisk, a Norwegian delicacy consisting of partially fermented fish. Having just succeeded with making rakefisk (winning several prizes), the barn burned down. With all the goats gone, their horizon was opened up. They could have decided on a new and different frontier, but as their children were very determined that a farm with only fish production was not a real farm, they rebuilt the goatbarn, this time according to modern principles and with possibilities to feed the goats with hay, that is supposed to be good fodder for organic cheese making. "We saw that local cheese making for sale would be allowed sometimes in the near future," they said. Tore and Inger were thus a bit ahead of their time. Today all the goat milk produced on the farm goes into their cheese making, and they produce several sorts of cheese. Starting out, they had a small room for production, a few years later they built a cheese factory and, in the same building, a farm shop and a hall for serving. At first only a small hall, but a few years later a second storey was added to the house to make room for conferences and serving large groups of people.

For, as Inger says: people just started coming. Hearing about the rakefisk and the cheese, people came to see and taste. And there are constantly new products to be created 
and served: the most recent additions are kid meat in various forms, homed baked bread and biscuits. Inger says about the guests:

"Sitting up there (on the second floor), eating and having a good time by the fireplace, the question came up: 'Where are we going to sleep?' (And I thought:) Are we perhaps going to offer overnight accommodation, also? But we had a house, a brown house on the other side of the pond here that we built some 10-12 years ago. So, now we have overnight capacity for twenty people. (...) So, this is how it works - things are being demanded, and it builds up. We have lots of ideas for what we can do."

The tourist part of their business is expanding: Companies come for seminars and conferences, busses arrive with pensioners and people from clubs and organizations, families and groups of friends to fish in their lakes, rent boats and follow the hiking trails which go all the way into Sweden. They have picnic areas, and they offer guided tours. They arrange wedding parties and anniversaries. Guests who don't want to go outdoors can participate in milking, baking and cheese making. Inger is planning on arranging art exhibitions and courses of various sorts. Ideas just pop up, she says, ideas that represent new frontiers. They haven't had time to think where they are going or what goals they are aiming for. Their inspiration is the beauty of the place, positive feedback from guests and the enjoyment of work and realizing ideas. Their worries are the economic risks they are taking with all the investments, but as yet this has not become a closure.

\section{From Innovation to Cultural Improvisation}

From these two cases we see that the development of the farm has more in common with improvisation than planned innovation. According to Ingold and Hallam [17] the difference between cultural improvisation and innovation is that the former characterizes creativity by way of its process, the latter by way of its products. In the following we will explore the process - and by that the improvisational creativity which is always in the making.

Cultural improvisation Ingold and Hallam [17] argue is generative, relational, temporal and the way we work.

It is generative in the sense that the farm tourist enterprises are the outcome of a process that has taken time, is continuous and has been modified and adapted to fit in with manifold and shifting purposes. This flexibility is highlighted as a success criterion by most of the farmers. Mariann, who ran one of the most successful farm enterprises, illustrates the generative and regular character by explaining their experience. She says: "You can never come to a closure, I don't think. You can never sit down and regard the process as completed because then you will lose your customers. You have to be in constant movement and change." Innovation is crucial to the survival and growth of the business, she thinks. This may be a variant of the mantra "innovate or die", and it illustrates the regular character of the innovation process.
Involvements in tourism were described by many of the couples as happening by a combination of chance and adaptation to new circumstances. Some had a house or a cottage they did not use themselves, which they turned into a guesthouse. Others were looking for new opportunities in order for the farm to be attractive as well as economically viable for themselves and the generation to come. Mariann said: "At the start we didn't have any great plans and thoughts that this would give us a big income. The important thing was to make enough money to cover the expenses of maintenance and renovation of all the old houses." Trygve at one of the other farms told the following story of how he and his wife Berit started the process:

"It began with a discussion in our family
three years ago. We have five grown- up
kids and we didn't want them to feel obliged
to take over the farm. We have built and
invested quite a lot in the farm since the
1970's. (...)Two of our children gave
positive response to trying additional
activities on the farm, and last year we
started a family park. (...) We hope to build
up a sustainable business until the young
generation is ready to take over. We do
have a feeling that they will not necessarily
continue with conventional farming as we
have done. We have a dream that if
everything develops successfully, it will be
possible to build a small restaurant and
start serving our own products from the
farm".

The similarities between the farmers' stories are the route involved. The route was taken step by step, where they did not have a clear-cut plan from the start on how to reach the transformation that they were doing to the farm. When they succeed, they reinvest the profit as well as their own experience in order to try out new ideas.

Improvisations are also relational. As illustrated in the quote above, relations within the family are important. Olaug and Harald tell their story of how their business developed from the local and natural resources:

"This farm has been in the family since the first wave of immigration from the south toward the north in the late 1700s. We started to imagine what it was possible to do on this farm. The barn was about to fall to pieces, and it was not an option to build a modern cowshed - and then we decided to rebuild the barn as a restaurant. Later we realised that we could take advantage of the fact that there is a bat colony on the property; it could be part of what we could offer to interest the people who visited. Then by chance some geologist came by, and he told us that there were some unique geological formations not far from the farm; we started to find a way where these could be brought together into a product. We saw the need to educate ourselves in storytelling, and we will use local resources in the dissemination of culture, natural 
landscape, and local food .... We also work with and learn from a researcher at the Museum to set up a system where the bat colony is monitored and where this monitoring can become part of a tourist product in the future."

The example above clearly communicates the relational quality of improvisations where knowledge and the application of knowledge play a central part.

The relational characteristics of improvisations are also seen in the way the products are formed by responses from customers. Mary, who ran a tourist business together with her husband on a very old farm site in a mountainous area, had developed a farm museum and said this about how the idea had come into existence:

\section{"The guests have inspired and encouraged $m e$, and they have actually also made me more interested in the old artifacts that we have grown up with here, you know. In earlier times, customs and practices were different - so, it ought to be of interest here. But, it is them, the guests, who have convinced me in many matters (...) and then ... then you get a boost and more faith in it.",}

Stories can be told as well as experienced, and by this means the lives of the ancestors as well as their own lives are made important. The above quote is an example of how the guests become part of the process of expanding the horizon and help develop a product that may be interesting from their point of view. Thus, the guests can be seen as co-innovators as they contribute to new forms of tourist experience.

Most of the farmers we interviewed had guests who came back every year, doing their booking for the next season in order to make sure they could return. The farm became in a sense a common project that visitors could take part in, where they could make their own paths and tracks, and enjoy participating in the creation of a space where the speed, complexity and often unpredictability of their everyday lives could be escaped. Nevertheless, the challenge for the farmers at times became to recreate distance from the visitors, as seen in the case description of the Seaside farm.

As mentioned, the concept of imaginative horizons [27] may be used in order to investigate the first faculty of entrepreneurship, which is openness and closure, and ways we construct horizons that determine what we experience and how we interpret what we experience. It is related to what we see as possibilities as well as those closures that are of our own making. For the farmers in the study, new ways of running the farm appear as a possibility; at the same time as, as Crapanzano highlights, there are other ways not possible to see. We would argue that imaginative horizons should be seen in relation to the tasks the farmers are capable of integrating imaginatively but also of embodying. As one of the farmers formulated it; you need to have the willingness to give yourself to others - and by this create a space of inter-subjectivity where differences between hosts and guests collapse and assemblages are made. By the farmers' imaginative willingness to give something of themselves, they create the between that makes possible the expansion of the horizon.

As we have seen, coming up with a "new idea" involves a relational process with family, guests, experts and the community. In the beginning the idea might be vague, fragile, vulnerable and incomplete if articulated at all, as with the successful entrepreneur who wanted to become a Sami as a child. The idea needs both protection and inspiration in order to be formulated for others and be seen as something new. In this first phase of an innovation, people seem to use others that they trust, that are already integrated in a network of meaningful relations [29]. By this the idea becomes meaningful and can take up further inspiration as well as being worked on from those involved.

\section{Temporality: Imagining the Past in the Future}

A third element of improvisation according to Ingold [28] is temporality. In this section we will further explore the temporalities that are imbedded in the innovation process.

For the farmers innovation involves bringing relations between the past and the future together. Heritage and history is a central part of the ground from where the improvisations are made. The tracks of the generations that have put their marks on the buildings and landscape as well as the paths of the animals - are part of the stories that enter into the products that they offer the tourists. Since all the enterprises are farms, the rural/farm heritage is an important aspect of their products. Some try to create an illusion of peasant farming in earlier days with many small animals around the farm yard. Others let the old buildings and stories about the farm and its history represent the cultural framework for the visit. Particularly in one part of the country where we did our field work, they have conserved the houses the way they were in the $1600-1700^{\text {th }}$ century with old Norwegian rose painting on the ceilings and furniture. One of the hosts claimed that guests might expect farm tourism to be about travelling 200 years back in time. However, normally the enterprises are keen to combine the modern with the traditional. The place and the buildings may be old, but the standard is contemporary. "Renewal through tradition" is a slogan used by one of the farmers.

Imagination, Hastrup [23] argues, is the link between history and action. We need the pasts in order to tell our stories of fulfilment and the stories of our discoveries or innovations. "...imagination is what makes present action meaningful by making anticipation possible, and because imagination also makes the creative agent perceive that intention and consequence are not one and the same" ( $p$. 204). They just work on different temporalities. Tradition then becomes dynamic rather than deterministic, inspirational rather than ideological. To set the farmhouse or a barn, built by a former generation, in a better condition for the visitors and the generations to come, was a source of inspiration for quite a few of the farmers. Innovation becomes what we may frame as a "carrying-forward" of all those events that have been culturally and historically transmitted.

How then does past history work itself into the innovation process, as well as what other sources of inspiration are put to use. Olaug said; 
"We entered the program "telling as a means of livelihood", and through the workshops the confirmation came; we could make a product out of local history. We searched the archives and church accountancy books; as well as made interviews with Harald's relatives in search of interesting stories from this farm and from this area. One of the persons we found was a tar maker from Pajala in Finland who moved here and settled with his wife and a young son. So then we did some more research on historical archives and combined it with a technique we learned from the study programs. We made a performance about the life of ancestors and we got much recognition and positive responses that told us that we were on the right track.... When it comes to knowledge of culture, then we need to research those people who used to live on the farm in the past. When it comes to knowledge of nature, then we need to enter and learn about the mountains here, geology, metal deposits and the history going back to the glacial epoch, where the formation of these mountains took place. There are several histories in this area; there is the short history relating to Døla-culture ${ }^{3}$ and the settlers that came here 200 years back in time, and then there is the long history of the Sami that used to live here and use the area before the settlers came and took up farming. And then there is the geological and biological history. We learned about bedrock from a researcher who came here to visit and who knew the area as well as his own pocket, and after that we have asked other researchers to teach us and help us find places and formations of interest".

Olaug's story illustrates that the innovation process takes inspiration from different sources. We notice the long and short history of the area and the farm, as well as the knowledge and skills coming from how things were done and how it can be done in the future. This is all within the process of forming their own present as well as the product. The past as well as the tourist product are performed and transformed in relation to how the tourists respond to the event they participate in. Bringing researchers into the process gives them inspiration and it gives the tourist product authenticity. Their imagining of the future of cultural tourism, "telling as a means of livelihood" is part of the process of new horizons.

\footnotetext{
${ }^{3}$ Around 1790 the Norwegian government set up a program to raise the number of Norwegians in the area. This was due to the dispute between Norway and Sweden on the national borders; where in fact the Sami population was migrating from Sweden to Norway for summer-pastures and back again in the autumn. The Norwegian government recruited farmers from southern areas like Gudbrandsdalen and Sætersdalen, offering them free land as well as free transportation north. Many did go and ancestors of these settlers still speak a specific dialect, identified as "døl".
}

The ideas also need to be set in circulation for others to take interest and for others to invest themselves in the unpredictability of what is to come. There are many considerations to be taken in this process. Not the least when it comes to local resource management regimes. Those innovating in areas that are possibly disputable, take this into consideration when they develop new products, for instance when it comes to fishing or hunting. Then they ask for restrictions in order to have the formal boundaries they need to inform the tourists who come. In areas where they know there is already pressure on the hunting-ground, this is not made part of the products that they offer. This even happens when it comes to history and storytelling, as one of the entrepreneurs put it; "you have to be aware as people in the local community see strangers as both exciting and annoying". Harald framed this in relation to knowledge:

"What motivated us was the desire to
systematize and carry on knowledge;
knowledge about the place, the farm and
knowledge about the cultural landscape.
And in our experience there is a sense of
interest in the market for this matter. From
our point of departure this should be
something to live for, not only something to
live off. So, there is the quest for continuity,
at least to some extent. And there is an
increasing demand for viable, ecological
development-all these new words that are
spoken..."

In order to set the idea into circulation, involvement from the locals becomes important. Harald continued: "We see it as necessary to bring people from the village into our project. We ask them to guide or to help out when there are bigger parties." When tourists take interest in the history of the place, and when the locals are given the chance to participate, they take pride in what they have and the story they are part of. When an area is used for different purposes, there are often strong emotions involved, some told us. This has to be taken seriously in order to set up a tourist enterprise that does not create conflict among people in the locality.

\section{DISCUSSION AND CONCLUSION}

In this article we have used the concept of imaginative horizons to characterize the transformative process of turning a farm into a farm based enterprise. As we have shown, innovations in farm tourism are improvisational, happening step by step, always imagining a new horizon. The process was described by the farmers as happening through a combination of chance and adaptation to new circumstances. They did not have a ready made project plan when they started. Rather, they started out on a very small scale, to try out the idea and avoid unnecessary economic risks that could threaten the farm. The gradual development meant that their focus did not need to be so much on closures or risks. Rather, the gradual expansion had prepared their bodies as well as their communities for the new horizon to appear.

Following Ingold [28] we have argued that the innovation process relates to improvisations that are not only generative, but also relational, temporal, and the way we 
work. More or less by chance, family, guests, the local community and other knowledgeable persons, enter into the innovation process. People are involved in an interactive process which involves accommodating oneself to diversions, obstacles, and responses that may not be exactly what they expected. These encounters may change the directions of the innovation process; when other people and other concerns are taken into consideration; opening up new horizons for those involved. Their aspiration lies at the end of the journey, where the horizons change but still can never be reached.

Concerning temporality, it is the same process that affirms traditions, that brings change and innovation to the place; making former generation's tracks and connections with nature and the animals vivid and meaningful, mostly for the hosts but to some extend also for the guests. Imagination, one could argue, is the link between history and action. We need the past in order to tell our stories as well as the stories of innovations. People grow into knowledge and skills, into pasts as well as futures in the very process of forming their own.

Following Ingold and Hallam [17] we have also seen that innovation and creativity are inseparable from the way we work with the material that surrounds us. The belief that creation relates to a pre-existing virtual form, a plan that was designed in advance, is deeply rooted in modern thought, and needs to be challenged as it takes away much of the energy needed when a process of creation is on the move. In our analysis this idea is challenged among other things as we argue that ideas take shape precisely in these movements. Creative agency brings the unprecedented into effect by way of imagination and thus it expands the farmer-entrepreneurs' own as well as the community's awareness of itself, forging their histories and traditions as they go along.

Research on innovation in rural tourism has gained momentum in recent years. There are, however, sharp differences within tourism, marking innovation processes as size, time and place specific. By focusing on small-scale farm tourism enterprises and studying innovation from a phenomenological perspective, this article has hopefully contributed to the understanding of some of the distinctive features of cultural innovation processes in the rural part of the tourist sector. Doing so it has confirmed some of what we already know from other studies of innovation processes in tourism - that they are small, incremental, relational, and often based on practice. What this study has added, is knowledge about their improvisational character, about how their incremental character relates to 'imaginative horizons', about the ways in which the innovation processes are relational and a part of the way we work. It has also put emphasis on the temporal. Farmers engaged in farm tourism innovate not only to change, but to sustain their farms as small-scale, household based and part of local, social relations. The analysis has seen a blurred boundary between new and old, and shown how the future is formed through an unfolding of resources that have been created in the past.

\section{ACKNOWLEDGEMENTS}

The authors gratefully acknowledge the funding by the Research Council of Norway and research funds made available by the Agricultural Agreement, HANEN, and Sparebank1 SMN.

\section{REFERENCES}

[1] Hall CM, Williams A. Tourism and innovation. London: Routledge 2008.

[2] Coombs R, Miles I. Innovation, measurement and services: the new problematic. In: Metcalfe JS, Miles I, Eds. Innovation systems in the service sectors. Measurement and case study analysis. London: Kluwer 2000.

[3] Sundbo J, Gallouj F. Innovation as a loosely coupled systems in services. In: Metcalfe JS, Miles I, Eds. Innovation systems in the service sectors. Measurement and case study analysis. London: Kluwer 2000.

[4] Hjalager AM. Innovation pattern in sustainable tourism. An analytical typology. Tourism Manage 1997; 18(1): 35-41.

[5] Hall CM, Müller DK, Saarinen J. Nordic tourism: Issues and cases. Bristol: Channel View Publications 2009.

[6] Hjalager AM. Repairing innovation defectiveness in tourism. Tourism Manage 2002; 23(5): 465-74.

[7] Pine J, Gilmore J. The Experience Economy. Boston: Harvard Business School Press 1999.

[8] Fuglsang L, Højland J, Sundbo J, Sørensen F. Innovation i oplevelsesvirksomheder. (Innovation in experience-based businesses). Report Centre for Experience Research. Roskilde: Roskilde Universitet 2008.

[9] Sundbo J. The Strategic Management of Innovation. Cheltenham: Edgar Elgar 2001.

[10] Gallouj F. Innovation in the Service Economy. Cheltenham: Edgar Elgar 2002.

[11] Aa W. van der, Elfring T. Realizing innovation in services. Scand. J Manage 2002; 18(2): 155-71.

[12] Miles I. Innovation in services. In: Fagerberg J, Mowery D, Nelson R. Eds. The Oxford Handbook of Innovation. Oxford: Oxford University Press 2004.

[13] Rønningen M. Innovation in the Norwegian Rural Tourism Industry: Results from a Norwegian Survey. Open Social Sci J 2010; 3: 15-29.

[14] Kvam GT, Stræte EP. Innovation and diffusion - Different roles in developing nature-based tourism. Open Social Sci J 2010; 3: 30-40.

[15] Nybakk E, Hansen E. Entrepreneurial attitude, innovation and performance among Norwegian nature-based tourism enterprises. Policy 2008; 10: 473-9.

[16] Nybakk E, Crespell P, Hansen E, Lunnan A. Antecendents to forest owner innovativeness: An investigation of the non-timber forest products and services sector. Forest Ecol Manage 2009; 257: 608618.

[17] Ingold T, Hallam E. Creativity and cultural improvisation: An introduction. In: Hallam E, Ingold T, Eds. Creativity and cultural improvisation. New York: Berg 2007; pp. 1- 24.

[18] Hughes-Freeland F. Tradition and the individual talent: T.S. Eliot for Anthropologist. In: Hallam E, Ingold T, Eds. Creativity and cultural improvisation. New York: Berg 2007; pp. 207-223.

[19] Schumpeter J. The theory of economic development. Cambridge, Mass: Harvard University Press 1934.

[20] Meyer S. Det innovative mennesket. (The innovative human). Oslo Fagbokforlaget 2007.

[21] Nordenström KA, Ridderstråle J. Funky business: med talent danser kapitalen. Oslo: Tano Aschehoug 2000.

[22] Kramvig B. The silent language of ethnicity. Eur J Cult Stud 2005; 8(1): 45-64.

[23] Hastrup K. Performing the world: Agency, anticipation and creativity. In: Hallam E, Ingold T, Eds. Creativity and cultural improvisation. New York: Berg 2007; pp. 193-207.

[24] Urry, J. Mobilities. Cambridge: Polity 2007.

[25] Sheller M, Urry J. The new mobilities paradigm. Environ Plan A 2006; 38: 207-26.

[26] Jackson M. Excursions. Durham: Duke University Press 2007.

[27] Crapanzano V. Imaginative horizons. Chicago, US: The University of Chicago Press 2004. 
[28] Ingold, T. Introduction. In: Hallam E, Ingold T, Eds. Creativity and cultural improvisation. New York: Berg 2007; pp. 45-54.
[29] Fosseli Olsen E, Kramvig B. Kultur som næring - møter som sammenstøter? (Culture as industry; meeting or encounters?) Magma 2009; 9: 22-9.

Received: October 30, 2009

(C) Brandth et al.; Licensee Bentham Open

This is an open access article licensed under the terms of the Creative Commons Attribution Non-Commercial License (http: //creativecommons.org/licenses/by$\mathrm{nc} / 3.0 /$ ), which permits unrestricted, non-commercial use, distribution and reproduction in any medium, provided the work is properly cited. 